\title{
A Comparative Study on Attenuation of Stress Response During Direct Laryngoscopy and Endotracheal Intubation with Dexmedetomidine and Lignocaine in Central Kerala
}

\author{
Reshma Rajkumar ${ }^{1}$, Sunilkumar T.S. ${ }^{2}$, Remani K.K. ${ }^{3}$, Juby E.V. ${ }^{4}$, Shamsad Beegum T.S. ${ }^{5}$ \\ 1, 2, 3, 4, 5 Department of Anaesthesiology, Government Medical College, Thrissur, Kerala, India.
}

\section{ABSTRACT}

\section{BACKGROUND}

Direct laryngoscopy and endotracheal intubation have been a part of the mainstay modalities of providing anaesthesia. Both lignocaine and dexmedetomidine have proven effects of attenuating the stress response to laryngoscopy and intubation. This study compared the efficacy in attenuating the pressor response of lignocaine when given at $1.5 \mathrm{mg} / \mathrm{kg}$ and dexmedetomidine given at $0.5 \mu \mathrm{g} / \mathrm{kg}$ body weight.

\section{METHODS}

This is a prospective observational study involving 80 patients of both sexes who underwent elective surgeries under general anaesthesia. They were divided into two groups: Group D and Group L. Group D received dexmedetomidine $0.5 \mu \mathrm{g} / \mathrm{kg}$ body weight slow IV, 10 minutes prior to laryngoscopy and Group L received 2\% preservative free lignocaine $1.5 \mathrm{mg} / \mathrm{kg}$ body weight i.v. bolus ninety seconds prior to laryngoscopy. Hemodynamic changes like heart rate (HR), systolic blood pressure (SBP), diastolic blood pressure (DBP) and mean blood pressure (MBP) were monitored before induction (baseline), post induction and at 1, 5, and 10 minutes after endotracheal intubation. Structured proforma was formulated and obtained data was analysed using STATA software.

\section{RESULTS}

In the lignocaine group, heart rate, SBP, DBP and MAP increased and gradually returned to baseline value. The dexmedetomidine group showed highly significant attenuation of sympathetic response to laryngoscopy and intubation compared to lignocaine groups.

\section{CONCLUSIONS}

The study results go on to demonstrate that dexmedetomidine infusion is better at attenuating the pressor response to intubation than preservative free intravenous lignocaine when given prior to induction.

\section{KEY WORDS}

Stress Response, Direct Laryngoscopy, Intubation, Dexmedetomidine, Lignocaine.
Corresponding Author: Dr. Sunilkumar T.S., Associate Professor, Department of Anaesthesiology, Government Medical College, Thrissur-680596, Kerala, India. E-mail:drsunilts@gmail.com

DOI: $10.14260 / \mathrm{jemds} / 2021 / 802$

How to Cite This Article: Rajkumar R, Sunilkumar TS, Remani KK, et al. A comparative study on attenuation of stress response during direct laryngoscopy and endotracheal intubation with dexmedetomidine and lignocaine in Central Kerala. J Evolution Med Dent Sci 2021;10(45):3973-3977, 10.14260/jemds/2021/802 DOI:

Submission 24-10-2021,

Peer Review 30-10-2021,

Acceptance 22-12-2021,

Published 28-12-2021.

Copyright (c) 2021 Reshma Rajkumar et al. This is an open access article distributed under Creative Commons Attribution License [Attribution 4.0 International (CC $B Y 4.0)]$ 


\section{BACKGROUND}

Laryngoscopy and endotracheal intubation are essential tools in the hands of an anaesthesiologist in maintaining the airway. Laryngoscopy and tracheal intubation in adults are commonly accompanied by sympathoadrenal responses. The magnitude of hemodynamic changes observed may be dependent on various factors such as depth of anaesthesia, whether any measures are taken prior to airway manipulation, the anaesthetic agents used, the duration of laryngoscopy and intubation. The principle mechanism in hypertension and tachycardia is the sympathetic response which may be the result of increase in catecholamine activity.1,2

Laryngoscopy stimulates airway reflexes which is a polysynaptic event where the afferents travel via the 9th and 10 th cranial nerves to the brain and spinal cord. An efferent sympathetic response results in norepinephrine release from nerve terminal, epinephrine release from adrenal gland and activation of renin angiotensin aldosterone system. The increases in the pulse rate and blood pressure are usually transitory, variable and unpredictable. These responses are probably of no consequence in healthy individuals but either or both may be hazardous to those with hypertension, myocardial infarction or cerebrovascular diseases.

Pressor response is exaggerated in hypertensive patients even though rendered normotensive pre-operatively by antihypertensive medication. ${ }^{3}$ Pressor response may result in intraoperative myocardial infarction, acute left ventricular failure, dysrhythmias and intracranial bleed in individuals with end organ decompensation. ${ }^{4}$

Attempts were made as early as in the 1960 s by various investigators to reduce the pressor response to laryngoscopy and tracheal intubation using various inhalational anaesthetic agents and other pharmacological agents.

Inhalational anaesthetic agents like ether and cyclopropane, trichloroethylene, chloroform and ethyl chloride were used to obtund the laryngoscopic responses by increasing the depth of anaesthesia. However, they were associated with stormy induction and longer time for achieving sufficient alveolar concentration, thereby their use for attenuating the laryngoscopic response were not of much use.

The utilization of halogenated hydrocarbons like halothane and enflurane, vastly improved the use of inhalational anaesthetic agents for blunting the laryngoscopic responses. However, as the depth of anaesthesia increased, the myocardial depression caused by these agents also increased, leading to increased risk of bradycardia, hypotension and dysrhythmias.

Robert K Stoelting, noted that the best way to prevent laryngoscopic reaction was to reduce the duration of laryngoscopy and intubation. ${ }^{5}$ He noted that if laryngoscopy and intubation were performed within 15 seconds, the hemodynamic responses seemed to be minimal. He also suggested that IV lignocaine given in the dose of $1.5 \mathrm{mg} / \mathrm{kg}$ body weight sufficiently attenuated the laryngoscopic reaction.

In 1973, Practolol (Prys Roberts et al., 1973) was the first beta blocker used for attenuating the pressor response to laryngoscopy and tracheal intubation. Later many other drugs with beta blockade activity were tried to control the laryngoscopic reactions like acebutolol, propranolol and labetolol. 6 The authors noted that, though these agents were effective in blunting the laryngoscopic reactions, their onset of action was rather delayed and duration of action was prolonged, thereby increasing the risk of development of bradycardia in the perioperative period.

In 1989, Kallio et al. ${ }^{7}$ studied the effects of dexmedetomidine on hemodynamic control mechanisms. Authors concluded that higher doses of dexmedetomidine (50 and $75 \mu \mathrm{g}$ ) decrease blood pressure and heart rate with initial small hypertensive response due to activation of postsynaptic $\alpha 2$-receptors.

In 2006, Yildiz et al. ${ }^{8}$ studied the effect of single pre induction intravenous dose of dexmedetomidine $1 \mu \mathrm{g} / \mathrm{kg}$ body weight on cardiovascular response resulting from laryngoscopy and endotracheal intubation, need for anaesthetic agent and perioperative hemodynamic stability in fifty patients undergoing elective minor surgery under general anaesthesia. Authors concluded that preoperative administration of a single dose of dexmedetomidine resulted in progressive increase in sedation, blunted the hemodynamic responses during laryngoscopy and reduced opioid and anaesthetic requirements without affecting the recovery time after the surgery.

In 2010, Ferdi et al. ${ }^{9}$ conducted a prospective, randomized, double blind controlled study to investigate the hemodynamic effect of intravenous dexmedetomidine as an adjunct to anaesthetic induction to attenuate hemodynamic response to endotracheal intubation in patients undergoing fast track coronary artery bypass grafting. Authors concluded that dexmedetomidine can be safely used to attenuate the hemodynamic responses to tracheal intubation in patients undergoing myocardial revascularization receiving beta blockers.

In 2011, Keniya et al. conducted a double-blind controlled study to assess the efficacy and safety of dexmedetomidine in attenuating sympathoadrenal responses to tracheal intubation and to analyse reduction in perioperative anaesthetic requirement. ${ }^{10}$ Authors concluded that dexmedetomidine as a premedicant is effective in attenuating sympathoadrenal responses to tracheal intubation with significant anaesthetic and opioid sparing effect.

Abou-Madi et al. in 1977 studied cardiovascular reactions to laryngoscopy and tracheal intubation following small 0.75 $\mathrm{mg} / \mathrm{kg})$ and large $(1.5 \mathrm{mg} / \mathrm{kg})$ i.v. doses of lignocaine in eighty ASA grade 1 to 4 patients and found that the higher dose was more effective in attenuating circulatory responses to tracheal intubation. ${ }^{11}$

This study compared the efficacy in attenuating the pressor response of lignocaine when given at $1.5 \mathrm{mg} / \mathrm{kg}$ and dexmedetomidine given at $0.5 \mu \mathrm{g} / \mathrm{kg}$ body weight.

\section{METHODS}

This prospective observational study was conducted in a tertiary care hospital in Central Kerala over a period of 1 year. After obtaining approval of institutional research and ethical committee (order no B6-8772/2016 MCTCR (12) dated 01/012/2018), 80 patients belonging to The American Society of Anesthesiologists, Physical Status classification 
system (ASA PS) I \&II, of either sex in the age group of 18-60 years, scheduled to undergo elective surgeries under general anaesthesia were included by consecutive sampling method. A study comparing the effects of intravenous lignocaine and dexmedetomidine on hemodynamic stress response to laryngoscopy by Saya Raghavendra Prasad, Uma Maheshwar Matam et al. was taken as the reference study for taking the values (MAP at 5 minutes post intubation) in both groups. ${ }^{12}$ $\mathrm{Z} \alpha-1.96, \mathrm{Z} \beta-0.84, \mathrm{~S}-9.99, \mu 1-94.6, \mu 2-88.12$ and used the formula $n=(Z \alpha+Z \beta) 22 S 2 /(\mu 1-\mu 2) 2$ to calculate the sample size and expected a $5 \%$ drop out rate $(80 \%$ power and $5 \%$ alpha error), hence, included 40 patients in each group. Laryngoscopy and intubation time were decided to be less than $15 \mathrm{sec}$. and in a single attempt. Patients with anticipated difficult airway, more than one attempt of intubation, duration of laryngoscopy and intubation of $>15$ sec. were excluded.

All patients underwent routine pre-anaesthetic evaluation and were optimized prior to anaesthesia. Routine and specific investigations were done. All patients had nil per oral for at least 8 hours prior to surgery and received tab. metoclopromide $10 \mathrm{mg}$, tab. ranitidine $150 \mathrm{mg}$, tab. alprazolam $0.5 \mathrm{mg}$ on the night before surgery. The details about the study were explained to all patients and informed written consent was taken. Peripheral intravenous line was secured and electrocardiogram, pulse oximeter and noninvasive blood pressure monitoring were attached. Baseline systolic blood pressure, diastolic blood pressure, mean arterial blood pressure and heart rate were recorded before induction of anaesthesia. Premedications were given with inj. midazolam $0.05 \mathrm{mg} / \mathrm{kg}$ i.v. inj. glycopyrrolate $0.005 \mathrm{mg} / \mathrm{kg}$, inj. fentanyl $1 \mu \mathrm{g} / \mathrm{kg}$ and inj. ondansetron $0.1 \mathrm{mg} / \mathrm{kg}$ slow i.v. After preoxygenation, induction with inj. thiopentone sodium $5 \mathrm{mg} / \mathrm{kg}$ and inj. vecuronium $0.1 \mathrm{mg} / \mathrm{kg}$ were given.

Inj. dexmedetomidine $0.5 \mu \mathrm{g} / \mathrm{kg}$ diluted to $10 \mathrm{ml}$ in normal saline given as an infusion 10 minutes before induction of anaesthesia using a syringe pump over 10 minutes to group D. Group L received $1.5 \mathrm{mg} / \mathrm{kg}$ of preservative free i.v. lignocaine diluted to $10 \mathrm{ml}$ with normal saline 90 seconds before intubation.

Post induction vitals were recorded. Short duration laryngoscopy and intubation was done with appropriate sized laryngoscopic blade and cuffed oral endotracheal tube. The endotracheal placement was confirmed and anaesthesia maintained intraoperatively with oxygen, nitrous oxide and isoflurane mixture at $33 \%, 66 \%$ and $0.2-1 \%$ respectively. Heart rate, systolic blood pressure, diastolic blood pressure and mean arterial blood pressure were measured at 1, 5, and 10 min post intubation.

\section{Statistical Analysis}

Data was entered in Microsoft Excel software and analysed using STATA software version 12 (manufactured by Stata Corp LP, College Station, Texas).

The continuous variables such as age and weight were summarised as mean and standard deviation in both groups. We summarised categorical independent variables like gender and ASA category as frequencies and proportions in both groups and the continuous variables like age, weight, hemodynamic parameters at different time points between the groups using the unpaired $t$ test. The distribution of participants based on categorical variables like gender and ASA category between the groups were compared using the chi-square test. $\mathrm{p}$ value: $0.01<\mathrm{P}<0.05$ considered as moderately significant and $\mathrm{P}<0.01$ as highly significant.

\section{RESULTS}

\begin{tabular}{|ccc|}
\hline & Group D & Group L \\
Age: Mean & 33.82 & 36.52 \\
SD & 8.9 & 11.1 \\
p value & 0.23 & \\
Weight: Mean & 61.55 & 57.68 \\
SD & 10.9 & 7.6 \\
P value & 0.07 & $15(37.5 \%)$ \\
Gender : Male & $17(42.5 \%)$ & $25(62.5 \%)$ \\
Female & $23(57.5 \%)$ & $26(65 \%)$ \\
& $\chi 2=0.21, \mathrm{p}$ value $=0.65$ & $14(35 \%)$ \\
ASA PS: 1 & $29(72.5 \%)$ & \\
2 & $11(27.5 \%)$ & \\
\multicolumn{2}{|c|}{ Table 1. Socio Demographic Characteristics } \\
\hline \multicolumn{2}{c}{}
\end{tabular}

Table 1 . The groups were comparable when the age was compared using unpaired t-test with $\mathrm{p}$ value 0.23 . The weight of participants was not significantly different between the groups with $\mathrm{p}$ value 0.07 . There was no significant difference in the distribution of gender ( $p$ value $=0.65$ ) or ASA categories $(\mathrm{p}$ value $=0.47)$

\section{Outcome Analysis}

Heart rate at different time points between the groups.

\begin{tabular}{|cccc|}
\hline Heart Rate & Group D & Group L & p value \\
Baseline & $88.28(15.6)$ & $88.62(11.6)$ & 0.16 \\
Post induction & $71.2(13.3)$ & $85.05(10.8)$ & $<0.001$ \\
1 Minute post intubation & $77.48(9.2)$ & $86.15(11.5)$ & $<0.001$ \\
5 Minutes post intubation & $73.42(10.2)$ & $82.78(12.3)$ & $<0.001$ \\
10 Minutes post intubation & $72.65(10.8)$ & $79.78(11.7)$ & 0.006 \\
\hline Table 2. Heart Rate at Different Time Points between the Groups \\
\hline
\end{tabular}

Heart rate was persistently higher in all points except baseline in the Group L compared to Group D. At baseline the heart rate was comparable between the groups with $p$ value 0.16 .

\section{Blood Pressure at Different Time Points between the Groups}

\begin{tabular}{|c|c|c|c|c|}
\hline & & Group D & Group L & p value \\
\hline \multirow{5}{*}{ SBP } & Baseline & $124.75(15.2)$ & $129.35(17.0)$ & 0.21 \\
\hline & Post induction & $100.65(10.9)$ & $104.78(15.3)$ & 0.17 \\
\hline & 1 Minute post intubation & $97.35(12.2)$ & $107.62(13.0)$ & $<0.001$ \\
\hline & 5 Minutes post intubation & $93.98(10.4)$ & $105.5(12.9)$ & $<0.001$ \\
\hline & 10 Minutes post intubation & $92.02(8.9)$ & $105.18(12.3)$ & $<0.001$ \\
\hline \multirow{5}{*}{ DBP } & Baseline & $80.48(12.5)$ & $83.7(13.0)$ & 0.26 \\
\hline & Post induction & $62.5(11.9)$ & $66.12(12.4)$ & 0.19 \\
\hline & 1 Minute post intubation & $60.6(9.9)$ & $71.4(10.0)$ & $<0.001$ \\
\hline & 5 Minutes post intubation & $57.9(9.1)$ & $68.85(11.0)$ & $<0.001$ \\
\hline & 10 Minutes post intubation & $56.45(9.5)$ & $68.42(12.7)$ & $<0.001$ \\
\hline \multirow{5}{*}{ MAP } & Baseline & $95.18(12.4)$ & $98.8(13.5)$ & 0.21 \\
\hline & Post induction & $75.28(10.7)$ & $77.98(12.6)$ & 0.30 \\
\hline & 1 Minute post intubation & $72.8(10.0)$ & $81.98(10.2)$ & $<0.001$ \\
\hline & 5 Minutes post intubation & $69.98(9.1)$ & $79.5(11.8)$ & $<0.001$ \\
\hline & 10 Minutes post intubation & $68.32(8.8)$ & $79.75(12.1)$ & $<0.001$ \\
\hline
\end{tabular}

Systolic, diastolic and mean blood pressure was persistently higher in all points except baseline and post induction in Group L compared to Group D. 


\section{DISCUSSION}

Laryngoscopy and tracheal intubation are considered as the most critical events during administration of general anaesthesia as they provoke transient but marked sympathoadrenal response manifesting as hypertension and tachycardia. ${ }^{13}$

Abou-Madi et al. have discussed the possible mechanisms to account for these observations with IV lignocaine. These include a direct myocardial depressant effect, a peripheral vasodilation effect and finally an effect on synaptic transmission.

Lev \& Rosen, et al. wrote a review on "Prophylactic lignocaine use pre intubation". They said that a dose of prophylactic lignocaine of $1.5 \mathrm{mg} / \mathrm{kg}$ given intravenously 3 minutes before intubation is optimal. ${ }^{14}$

Recently $\alpha-2$ agonists like clonidine ${ }^{15}$ and dexmedetomidine have been tried for suppressing the response to intubation and have been found to have better effects compared to all the drugs mentioned above. Clonidine is less potent $(\alpha-1: \quad \alpha-2=1: 220)$ compared to dexmedetomidine $(\alpha-1: \alpha-2=1: 1620)$ in its agonism to $\alpha-2$ receptors. Hence, dexmedetomidine may be a better drug among $\alpha-2$ agonists for suppressing the hemodynamic responses to laryngoscopy and intubation.

Kunisawa et al. used $1 \mu \mathrm{g} / \mathrm{kg}$ body weight of dexmedetomidine with fentanyl and found that vasoconstrictive effects of dexmedetomidine through $\alpha-2$ adrenoceptors which are located in vascular smooth muscle might be responsible for this suppression as a result of administration of higher dose. 16

Esra et al. used 0.5 and $1 \mu \mathrm{g} / \mathrm{kg}$ body weight of dexmedetomidine for suppression of intubation response and found that there was no significant change regarding HR in both doses. ${ }^{17}$

In our study the mean heart rate during use of dexmedetomidine decreased by $19.34 \%$ post induction from baseline values which is better than the effect by lignocaine (4.02\% decrease only) and at laryngoscopy though the heart rate increased, in the dexmedetomidine population it did not rise higher than baseline values. The values were still $12.23 \%$ lower. The p value is less than 0.05 for the post induction, at laryngoscopy, at 1 st minute, 5 th minute and at 10 th minute making it statistically significant. Thus, dexmedetomidine proves to be better in attenuating heart rate response to laryngoscopy and intubation. Basar et al. ${ }^{18}$ noted that following laryngoscopy and intubation HR increased by 10 bpm in the lignocaine group and in dexmedetomidine group the HR decreased by $8 \mathrm{bpm}$ which is statistically highly significant and similar to our study.

The mean SBP, post induction with both dexmedetomidine and lignocaine is found to have fallen. At laryngoscopy it can be seen that the values are consistently lesser $(22 \%)$ with dexmedetomidine; with lignocaine it is only $16.7 \%$ lesser than baseline. At 1-, 3- and 5-minute intervals after laryngoscopy it is evident that SBP using dexmedetomidine has fallen to a greater extent (22 to $26 \%$ fall) than with lignocaine (17 to $19 \%$ fall) which is statistically significant. Jaakola et al. ${ }^{19}$ also have observed a similar fall of $17 \mathrm{mmHg}$ in SBP 5 minutes after intubation in the dexmedetomidine group and in the control group an increase of SBP by $10 \mathrm{mmHg}$, compared to the basal values.
The diastolic BP, there was a $22 \%$ fall from baseline post induction, which was almost similar with dexmedetomidine and lignocaine. After laryngoscopy the fall in DBP with dexmedetomidine was sustained above $25 \%$ however, with lignocaine it can be seen to be only above $15 \%$ from baseline showing an obvious increase in diastolic BP while using lignocaine. At 1, 3 and 5 minutes thereafter the fall from baseline is higher with dexmedetomidine (25 to 30\%) as compared to lignocaine (15 to 18\%). Jaakola et al. ${ }^{20}$ observed a fall of DBP by $10 \mathrm{mmHg}$ in dexmedetomidine group compared to basal values which is less than that of our study (20 $\mathrm{mmHg}$ ) as the dose of dexmedetomidine used by the author was $0.6 \mu \mathrm{g} / \mathrm{kg}$ body weight when compared to $1 \mu \mathrm{g} / \mathrm{kg}$ body weight in our study.

The fall in MAP from baseline with dexmedetomidine and lignocaine post induction was the same. After laryngoscopy, dexmedetomidine continues to provide maximum attenuation of pressor response. At 1, 3 and 5 minutes thereafter the fall from baseline is higher with dexmedetomidine (21 to $28 \%$ ) as compared to lignocaine (17 to $19 \%$ ). Mowafi et al. ${ }^{20}$ observed a decrease in MAP by 13 mmHg in the dexmedetomidine group which concurs with our study.

\section{CONCLUSIONS}

The results clearly confirm that both dexmedetomidine and lignocaine attenuate the pressor response to laryngoscopy and intubation. The attenuation of the pressor response is by far greater with dexmedetomidine than that by lignocaine. Therefore, in patients whose pressor response to intubation can be detrimental, dexmedetomidine appears to be a better alternative to preservative free lignocaine.

Data sharing statement provided by the authors is available with the full text of this article at jemds.com.

Financial or other competing interests: None.

Disclosure forms provided by the authors are available with the full text of this article at jemds.com.

\section{REFERENCES}

[1] Kayhan Z, Aldemir D, Mutlu H, et al. Which is responsible for the hemodynamic response due to the laryngoscopy and endotracheal intubation? Catecholamines, vasopressin or angiotensin? Eur J Anaesthesiol 2005;22(10):780-5.

[2] Morin AM, Geldner G, Schwarz U, et al. Factors influencing pre-operative stress responses in coronary artery bypass graft patients. BMC Anaesthesiol 2004;4(1):7.

[3] Prys-Roberts C. Anaesthesia and hypertension. Br J Anaesth 1984;56(7):711-24.

[4] Fox EJ, Sklar GS, Hill CH, et al. Complications related to the pressor response to endotracheal intubation. Anaesthesiology 1977;47(6):524-5.

[5] Stoelting RK. Circulatory changes during direct laryngoscopy and tracheal intubation: influence of duration of laryngoscopy with or without prior lignocaine. Anaesthesiology 1977;47(4):381-4. 
[6] Chung KS, Sinatra RS, Chung JH. The effect of an intermediate dose of Labetalol on heart rate and blood pressure responses to laryngoscopy and intubation. J Clin Anaesth 1992;4(1):11-5.

[7] Kallio A, Scheinin M, Koulu M, et al. Effects of dexmedetomidine, a selective alpha 2-adrenoceptor agonist, on hemodynamic control mechanisms. Clin Pharmacol Ther 1989;46(1):33-42.

[8] Yildiz M, Tavlan A, Tuncer S, et al. Effect of dexmedetomidine on hemodynamic responses to laryngoscopy and intubation: perioperative hemodynamics and anaesthetic requirements. Drugs RD 2006;7(1):43-52.

[9] Menda F, Köner O, Sayin M, et al. Dexmedetomidine as an adjunct to anesthetic induction to attenuate hemodynamic response to endotracheal intubation in patients undergoing fast-track CABG. Ann Card Anaesth 2010;13(1):16-21.

[10] Keniya VM, Ladi S, Nahpade R. Dexmedetomidine attenuates sympatho-adrenal response to tracheal intubation and reduces perioperative anaesthetic requirement. Indian J Anaesth 2011;55(4):352-7.

[11] Abou-Madi MN, Keszler H, Yacoub JM. Cardiovascular reactions to laryngoscopy and tracheal intubation following small and large intravenous doses of lignocaine. Can Anaesth Soc J 1977;24(1):12-9.

[12] Prasad SR, Matam UM, Ojili GP. Comparison of intravenous lignocaine and intravenous dexmedetomidine for attenuation of hemodynamic stress response to laryngoscopy and endotracheal intubation. J NTR Univ Health Sci 2015;4(2):86-90.

[13] Prys-Roberts C, Green LT, Meloche R, et al. Studies of anaesthesia in relation to hypertension II. Hemodynamic consequences of induction and endotracheal intubation. Br J Anaesth 1971;43(6):531-47.

[14] Lev R, Rosen P. Prophylactic lignocaine use preintubation: a review. J Emerg Med 1994;12(4):499506.

[15] Kulka PJ, Tryba M, Zenz M. Dose response effects of intravenous clonidine on stress response during induction of anaesthesia in coronary artery bypass graft patients. Anaesth Analg 1995;80(2):263-8.

[16] Kunisawa $T$, Nagata 0 , Nagashima $M$, et al. Dexmedetomidine suppresses the decrease in blood pressure during anaesthetic induction and blunts the cardiovascular responses to tracheal intubation. J Clin Anesth 2009;21(3):194-9.

[17] Sağıroğlu AE, Celik M, Orhon Z, et al. Different doses of dexmedetomidine on controlling hemodynamic responses to tracheal intubation. Internet J Anesthesiol 2010;27:2.

[18] Basar H, Akpinar S, Doganci N, et al. The effect of preanaesthetic, single dose dexmedetomidine on induction, hemodynamic and cardiovascular parameters. Journal of Clinical Anaesthesia 2008;20(6):431-6.

[19] Jaakola ML, Ali-Melkkila T, Kanto J, et al. Dexmedetomidine reduces intraocular pressure, intubation response and anaesthetic requirements in patients undergoing ophthalmic surgery. Br J Anaesth 1992;68(6):570-5.

[20] Mowafi HA, Aldossary N, Ismail SA, et al. Effect of dexmedetomidine premedication on the intraocular pressure changes after succinylcholine and intubation. Br J Anaesth 2008;100(4);485-9. 